\title{
The Arts and Crafts Linguistic Properties within the Communicative Context of the Conviviality Culture
}

\author{
Natalia Mostitskaya \\ State Institute of Art Studies \\ Moscow, Russia \\ mozt@ rambler.ru
}

\begin{abstract}
The article studies the communicative function of fine arts basing methodologically on the theory of the cultural ideal modeling within the individual's memory structure. The object of this research is the poetics of an art piece embedded into the festive rituals as a specific message aimed at creating the conviviality itself, whilst appealing to the sensual, emotional and affective perception of an individual to be transformed into the cognitive perception of actual events, as well as verbal information transmitted in the festive communication medium. The arts and crafts pieces are considered as representatives of the festive communication.
\end{abstract}

Keywords-language of art; communicative conviviality medium; arts and crafts; festivity; ideal; sacralization system; conviviality and routine

\section{INTRODUCTION}

The communicative conviviality medium is the broadest matter for research. The role of fine arts in creating such a medium is highlighted in various papers. In particular, we consider the process of communication as a cultural creativity perceived through the theory of communication and the philosophical concept of culture as ideal-forming existential stage [1].

Studying the ideal-forming process within the individual consciousness as a kind of reflection was scrutinized by Hegel, who wrote a lot on fine arts, proposing also the concept of the ideal in art [2]. D. Pivovarov interpretation of the Hegel's reflection theory enables somehow instrumental studying of fine arts applied to the festive communications using the case studies of arts and crafts pieces. In particular, the article coins the "sacralization" concept helping to explore fine arts as a toolkit lending an event, personality, idea, things the property of "sacredness", facilitating thus translation and memorization of the key ideas and values, that structures some specific festive communication medium [3]. The festive event is represented as an act of cultural creativity landmarking the value orientations and other basic structural elements imprinted into the individual memory.

\section{FORMAT ION OF CULTURAL ST ANDARDS}

According to many studies, the feast itself is based on some sacred idea bringing people together to become a collective [4]. So, believing that collective "co-creation" contributes to the formation of cultural standards for each participant in the event, we focus on the cases of collective interaction in festive communication. Methodologically, we consider the communication theories and ideal-forming [5] [6]. Structuring a culture or a festive event using the collective communicative, "co-creation" is being unfolded through the sacralization logics, because the feast itself adds to the celebrated event the idea, the things, the personality the property of "sacredness", idealizing it by inclusion (or actualization) of the standard into the cultural worldview of those involved.

The sacralization insight, proposed by D. Pivovarov, is similar in its logical model to the memory structure designed by A. Sokolov, the renowned specialist in the theory of communication. [7]. This mnemonic model comprises the following sections: conceptual, semantic (or verbal logical), affective, motorial and apperceptive, each of which bears the semiotics and informational structure of its own. We envisage the situation, when the transmitted information through all the channels coincides, because these diverse linguistic structures translate the same idea, making the information coherent in relation to the idea in point. Thus, we face the maximum impact of this idea on the individual memory, including the cases of collective synergy intensifying the influence of information flows over the individual conscience. This means, that information is sure to be kept in memory for a long time to be used as a kind of a "prism" or a "cultural ideal" embedded into the worldviews, representing a range of specific phenomena and a filter for new information to be perceived.

In this article, we assume that art pieces used in festive rituals are deliberately designed to fine-tune the coherence of communication channels. Detailed description of the me mory directories induces parallels with the elements of the languages of various fine arts, constituting the image of a piece, as well as of that of a feast in general. Thus, the conception channel, comprising "the memory of concepts and perceptions received through the senses", includes images of diverse events experienced by an individual through his life. At the same time, the events directly related to the values are often memorized solidly. In essence, the conception directory is a visual channel of communication influenced by all types of fine arts through the imaginative power of these. 
The semantic directory contains the "memory for words, concepts, statements, abstract ideas" [7]. It should be noted, that the core of each culture is a sacred text verbalizing the values and defining the meanings in terms of given culture, preserving thus the spiritual integrity of a culture upon the semantic basis. This text broadcasted in a situation of festive communication is a case of artistic interpretation of sacral cultural info by means of belles-lettres and performing arts.

Affective directory is the storehouse of positive and negative emotions, "memory of the heart", actuated in the course of sensual and emotional perception. The basic values of culture are broadcasted through the emotionalization of the message packed in an art piece. It is art that, thanks to its "virulence" and excellent performance, induces the most valid emotional reaction helping to perceive the conveyed verbal text or the sacred idea easily the most. Therefore, in each culture, the fine arts are important to the utmost, since such transmission of meanings is most organic for individual perception, because artistic expression facilitates the verbal structures to be acquired by all areas of the memory.

The motorial directory of the memory is the "set of reactions to the stimuli that control behavior" [7]. This is another key section, indicating the need for "living insights" to render the meanings, through specific practical actions elaborated in ritual activities. The motorial section of the me mory also deals with diverse communication channels to be directly encrypted into the semiotics of the body language. It is not occasional that festive activities expressed in ritual actions are aimed at strengthening the effect of verbal and visual messages.

Apperception is the preservation of individual selfidentity through forming some personal set of values correlating one's own experience, sacred ideals and practices propagated by the society. This process is meant to synthesize all information flows generating, as a result, the semiotic worldview context. This kind of ideal processes is the basis of cultural expression.

Therefore, the modeling of artistic festive medium is to structure the individual worldviews based on sacred values. The synthesis of fine arts in the festive communicative medium is carefully traced in the texts of Pavel Florensky, who paid special attention to arranging the festive air within the temple space by combining different types of fine arts in order to convey and uncover the Christian ideals. P. Florensky, in his study on the temple space as an art synthesis, also touches upon the complex impact of art pieces on the perception of sacred truths during festive ceremonies, in addition to works of fine and decorative art, encompassing rituals, music, taste sensations etc.

The synthesis of fine arts conceives the synergy, accompanying inherently any festive event. The festive synergy is the basis of transcendental communication with the sacral ideas of culture. Thanks to aesthetically contagious artistic forms, the festive medium and sacred meanings are eagerly and naturally perceived by the audience as their own and true ideas. Thus, through the language of fine arts, the faith in the just transmitted ideals is meant to be originated.
The very form of a feast is special communicative media designed according to a certain model of message structuring that conveys the basic value concepts of a certain culture. In fact, the festive ceremony merely sacralize the values and ideals of culture. According to D. Pivovarov the sacralization system consis ts of:

- assortment of ideas sacred for a given society, that is the verbalization of ideology, which is briefly fixed in corresponding texts, and is most often disclosed in belles-lettres pieces. This system element relates to the verbal-logical section of me mory;

- psychological methods and techniques of persuading people of the absolute truth of the ideas directly related to the impact on faith in its various aspects, which are effective the most through emotional presentation of an idea to address to affective directory of the memory;

- specific symbolic avatars of sacred objects, sacramental and hostile symbols, which are widely visualized, especially basing compositionally on sacral symbolism to be stored in the conceptual area of the memory;

- some special organization, and most often the representatives of this or that ideology, who, through their practice and their example, implement the declared ideas. Being affiliated to such an organization, recipient-oriented approach maximally activates the directory as sociated with apperception;

- special practices, rituals, ceremonies inducing certain physical actions, even complex activities that are no longer just symbolic, but are also perceived physiologically. So, this information flow is routed to the motorial directory of the me mory [8].

Thus, the sacralization system described by D. Pivovarov, can be superposed onto the memory model by A.Sokolov to emphasize again transmitting and preservation of the cultural ideal as a value through the matters of structure and specificity. All these components displayed in a festive ceremony, along with art pieces involved, confirms the assumption that every element of the artistic festive medium contains the entire system of images and concepts uncovering the basic sacral idea of celebration.

Comparing these two methodological models, let's highlight the specific nature of their coordination, in particular, the affective me mory section - "the memory of the heart" is generated under the influence of the language of art. Therefore, emotionalization through the artistic image is a s pecial technique for translation of the sacred cultural values. The festive event itself appears to be an integral model of the entire system of sacralization, since the certain texts are uttered, certain people are present (the bearers of certain values) united by the idea of a certain feast, emotionalization is proceeded through external attributes, through works of art, and also through the ways of comprehension of symbols and ritual practices, including taste, tactile sensations, smell. Such a model of a festive event becomes in fact an integral 
information message transmitting the basic cultural values to be preserved, both in individual and social memory.

The feast model reappears as a holistic artistic image synthesizing the languages of various kinds of fine arts. Exploration of this model through the matter of sacralization is a new research method. This approach enables considering any organized feast as a technology of imprinting the basic ideals of culture and ideological attitudes in the structures of our memory, which function as a system for evaluation and motivation applicable to the forms of individual social behavior.

\section{ART AND CRAFT PIECES INTHE STRUCTURE OF FESTIVE COMMUNICATION}

The art piece in the structure of a feast is meant to translate the sacred symbols, the most significant images, and to contribute to general emotional at mosphere, which at the extremum ascend to the affect. Human emotional substance is the target of a art piece's influence. The author addresses to the audience skillfully simulating the emotional effect: "Gush forth my tears over a myth". At the same time, each epoch generates currently topical themes and images representing some contemporary values, evoking thus the emotional response from spectators.

Arts and crafts presuppose the function of a piece first of all, but at the same time the artistic performance is no less informative than for any work of fine art, bearing its own specificity in the design of artistic medium. It is crucial, that applied nature of arts and crafts, the tactile, sensory and motorial sensations are actualized (diverse perception channels resonance), which launches the imprinting of an event in the memory through the image of an object. The object becomes a kind of "catalyst" for memory or a representative of some festive event, and, accordingly, a message structured under the sacralization model algorith ms. Let us review several arts and crafts pieces used in mensal festive rituals of various periods.

The Severodvinsk grace cup "Fig. 1" was used to serve alcohol beverages at the festive table. Ritual collective drinking was often fairly necessary component of a festive event, and therefore the action itself acquired symbolic and material expression in a symbolic vessel. The artistic image of the cup fuses the following components: form, texture (material), ornamental composition, functioning. Moreover, the place on the table, where the grace cup should be positioned for its further use in the festive meal, was also a matter of great importance.

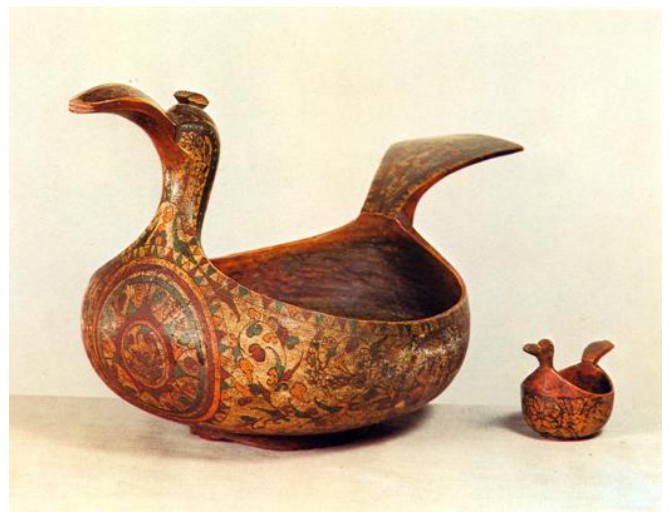

Fig. 1. The Severodvinsk grace cup.

The form of the piece reproduces the image of a waterfowl. The symbolism of a waterfowl traditionally denoted the connection of different elements (water and air) and different realms (the lower world and the world to come). At the same time (in the beliefs of the Slavs), water element, intermed iated by a bird, protects a person from the negative effects of this environment, i. e., sorting the spontaneous matter in some certain order our ascendants tried to protect their world, communicating thus with the surrounding nature. The ornamentation of this vessel features the signs of the Sun - a circle and floral ornament, which are well associated with the Severodvinsk paintings. The symbol of the Sun on the bowl under the high handle is read as a sign of integrity and harmony. The solar symbolism in ancient ornaments is also associated with fire motives, life orbit, eternal life, cycle of life and death, and served as a protective amulet. Specific functional and symbolic peculiarity is expressed in the very movement of hand using this cup, suggesting a gesture "scooping", and distribution of the drink among all the audience. This action involves the presence of some formal cupbearer, as well as following some formal process of distribution of the drink. The ritual presumes both the hierarchy, whilst equal sharing of the common good between all banqueters. The motorics accompanying the perception of this object directly implies the value of a collective united around some common good. At the same time, a common drink unites the tableful filled with the joy of general harmony in a single physical body at the biological level. Such a holistic state urges the "transition" of an individual into spiritual plain or even into extreme affect, unleashing maximu $m$ acceptance of the trans mitted values and ideals.

Thus, the symbolic medium of a thing and its applied function translate the idea of mediation between the spiritual and material worlds. The transition to another world occurs within a single "collective body" in somehow affective state, whilst the beverages perfectly "blur the boundaries of reality", thereby expanding each individual's communicative environment, bringing it to the level of transcendental interactions, that is peculiar to the festive communicative medium, since conviviality itself presupposes outstanding forms of ritual co mmunication with sacred cultural meanings The artistic image of a thing used in the ritual designates the boundaries of the communicative medium, symbolically 
fixing the interface between different worlds and the need for interaction and communication of these.

Conviviality is defined through the trance states, through conciliarity, through the involvement into some common chronotope [9]. In the case with the grace bowl, let's keep in mind that the object, placed generally in the center of the table, captures the attention of all audience with bright colorful décor and, at the same time, unites everybody in one within the conciliarity, meanwhile escalating the trance state, allowing to save in memory through the mnemonic sign of the object the experience of emotional "transition", which is always remembered as purely festive, together with all verbalized ideas. The thing used in the communicative ritual of a feast transforms into a kind of semiotic field of the event and the meanings conveyed therein. In everyday life, this thing becomes a symbol of this or that festive value. As to the grace cup, not only the rituals of wine drinking would remain in memory, but also those associated emotional sensations and verbally expressed ideas, which are perceived as fairly true in a state of affect. To enhance the coherence of information, the basic ideas are repeated many times in toasts, topics of conversation at a festive table, expressed by the event trendsetters trans mitting the basic meanings, as well as in communication situations, usual for certain commun ities.

In the recent past of Russia, the culture of the 1970s and 1980 s prescribed all average Soviet households to keep in standard cupboards crystal or porcelain utensils to be used exclusively for holidays, not for weekdays. This was a kind of festivity symbols and that "other" medium full of festive emotions, concentrating the basic self-identity strategies. Porcelain and crystal are very fragile materials used for arts and crafts. J. Baudrillard defined glass as a "charm of transcendence" [10]. The very fragility of the material symbolized the spiritual nature of festive communication. Memories of the spiritual world, actualized during feasts, are imprinted into the semiotics of everyday objects to be used in the festive ritual.

For example, a crystal salad bowl "Fig. 2" was exhibited on the table in festive ceremonies tanked with classic "Olivier" salad. As a rule, salad bowls are placed in the center of the table, and each guest replenish his plate on his own from a common salad bowl. At the same time, this ritual is quite alike using a grace cup. It is supposed to take common food, biologically uniting all the participants in the feast. Solar symbolism is also obvious in the decor of the salad bowl, which ornament bears even the shades of ancient sun and water worshipping. The artistic symbolism of such everyday things usually retains connections with prehistoric signs and meanings. Moreover, the salad bowl used in a solemn feast performed the decor function for the rest of the time, and in fact was a container for memories of the holidays and collectivism values, as well as transcendental communication (the difference in perception of transcendental media is related to the person's spiritual experience).

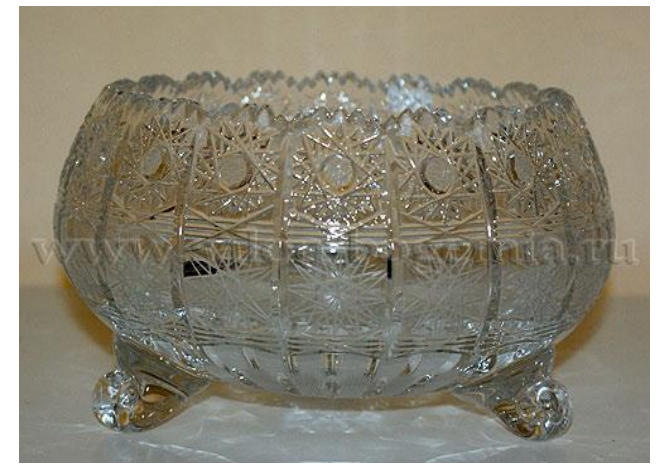

Fig. 2. A crystal salad bowl.

Any artwork, through devising an artistic image, enable recourse to the transcendental space. "The sign of transcendence" is the very capability of wising up the author's message and, therefore, his life values. Creating pieces, the artist translates his ideas into the language of emotions and feelings. For a viewer, this sensuality becomes a perfect guide facilitating the perception of values amplified by verbalized representation within the festive medium. Therefore, this information is reliably kept in the memory to become a means for assessing the actual occurrences. In other words, this is how the cultural ideal is formed within the actual reality structure.

The example of the Soviet jubilee tea service "Fig. 3" clearly traces the communist symbolism, the colors of the national flag, the coat of arms, and also the me morable dates celebrated in the USSR as the most important and decisive for the formation of the state: November ' 1917 - the Bolshevik Revolution, 1967 - the 50th anniversary of it... This service used at the festive table would undoubtedly remind the national values and ideals, along with the color symbolism in addition to the sacral meaning of the state attributes, would also reinforce the emotionalization of the event through natural influence of red.

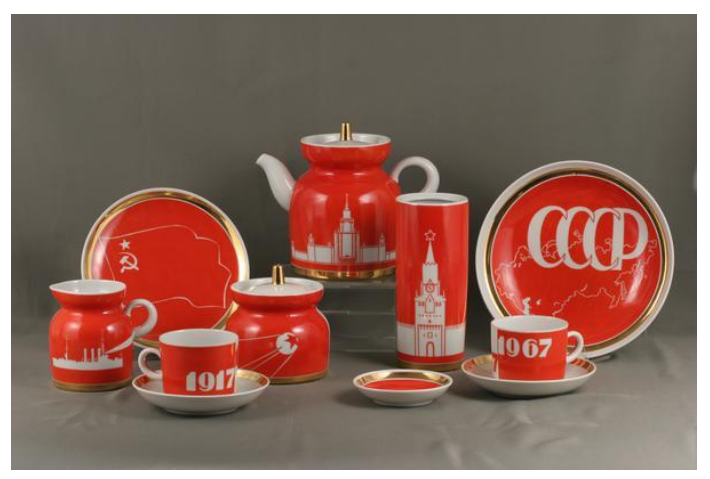

Fig. 3. The Soviet jubilee tea service.

\section{CONCLUSION}

The analysis of everyday things using the "festiveroutine" dichotomy inevitably detects the structural elements of an artistic image that contain the sacral cultural meanings actualized within the festive medium through coherent communication to be kept in the symbolis m of everyday household decor. A thing bearing the images of decorative 
symbols is marked by the festive rituals and the sacred meanings of a feast concept itself. In everyday life, a thing appreciated as arts and crafts piece is not used, but bears the social and individual me mory of the holidays, contributing to continuity and preservation of cultural values. It also serves as a standard for structuring the everyday communicative mediu m - verbal, visual, and motorial.

Thus, the linguistic peculiarities of art (arts and crafts pieces) in festive communication can be dealt with in the following concerns:

- Decoding the semiotics of an artwork directly includes individual emotional experience acquired in the course of a festive event, i.e. a spectator ascribes his emotional response to the object involved in a festive event, and "scans" the symbols of the decor as representational signs of values actualized during the feast;

- Being involved into a festive event, the subj remembers the cognitive perception of an artwork, which he then applies to the decor of the material piece in point;

- Thanks to the language of art and the technology of creating an artistic image, the affective image of the work is kept in the "memory of the heart", which facilitates the memorization of the verbal message transmitted within a festive event

- Arts and crafts pieces, functioning practically in the course of festive rituals, are intended to indicate the interface between the spiritual and material plains, to translate the idea of "transition to another space", in particular, "life-death-new life", thereby clueing the fundamental concept of feast as such.

When basing on the nuances of the art language and the examples of arts and crafts pieces overviewed herein, it becomes obvious that the ornamental symbolism mediates the real world of things and the imaginary world of values and ideals by constructing certain artistic images in the course of coherent perception of an artwork using all sense modalities. This artistic image is preserved in the individual's memory to become a repository of particular cultural ideals and a structural element of the personal mindset.

\section{REFERENCES}

[1] D. Pivovarov, History and Philosophy of Religion. Yekaterinburg, 2000.

[2] G.V.F Hegel. Aesthetics - M. Art, 1969-1971.v. 1

[3] D. Pivovarov. History and Philosophy of Religion. Yekaterinburg, 2000.

[4] K. Zhigulsky, Celebration and Culture. M.: 1985, p.127

[5] A. Sokolov, General Theory of Social Communication. St. Petersburg, Mikhailov Publishing House, 2002, p.57.

[6] D. Pivovarov. History and Philosophy of Religion. Yekaterinburg, 2000.

[7] A. Sokolov. General Theory of Social Communication. St. Petersburg, Mikhailov Publishing House, 2002. p.57.
[8] D. Pivovarov, History and Philosophy of Religion. Yekaterinburg, 2000, p.49.

[9] N. Mostitskaya, Feast of a Lifetime: the Christocentric Path of the Russian Intellectual (V. Voino-Yasenetsky - Archbishop and Surgeon). Krasnoyarsk, KSPU, 2010.

[10] J. Baudrillard, System of Things. M.: Rudomino, 1999. p.95. 